\title{
Glutamine Supplementation and Basketball Players Power Performance Changes
}

\author{
Murat Kaldirimci, Heidar Sajedi, Cemil Tugrulhan Sam, Orcan Mizrak and Hamit Kavurmaci \\ Department of Physical Education and Sport Science, University of Ataturk, Erzurum 0090, Turkey
}

\begin{abstract}
The aim of this study was to examine the efficacy glutamine ingestion on basketball players power performance. Forty men of a university basketball team (20.4 \pm 1.6 years; height: $188.6 \pm 8.7 \mathrm{~cm}$; body mass: $76.5 \pm 7.9 \mathrm{~kg})$ volunteered for this study. Subjects participated in four trials, each consisting of a 40-min basketball game with controlled time-outs for rehydration. During the FS (first trial), subjects were not allowed to rehydrate, and the total weight lost during the contest was used to determine fluid replenishment. During one trial subjects consumed only W (water), while during the other two trials subjects consumed the glutamine supplement mixed in water using either a low dose $(1 \mathrm{~g}$ per $500 \mathrm{ml})(\mathrm{G} 1)$ or high dose $(2 \mathrm{~g}$ per $500 \mathrm{ml})(\mathrm{G} 2)$. A $14.6 \%$ difference in basketball shooting performance was shown between FS and G1, and there was significant difference between FS and G1 for shooting performance at $P<0.05$. There was no significant difference in vertical jump power during any trial. Glutamine had significant effects on the reaction time at $5 \%$ probability level. It concluded that the test should be performed by different doses of the glutamine on the different sport team of men and women.
\end{abstract}

Key words: Glutamine, basketball, supplementation, shooting ability, reaction time.

\section{Introduction}

Glutamine is non-essential amino acid. In humans, glutamine is the most abundant amino acid in the body that is found in all tissues in the body such as plasma, with the largest storage area in skeletal muscle. The resting level of glutamine in the plasma has been reported to range between 550 and $750 \mu \mathrm{mol} \cdot \mathrm{L}^{-1}$, while glutamine concentrations within skeletal muscle is approximately $20 \mathrm{mmol} \cdot \mathrm{kg}^{-1}$ wet weight. There is glutamine in many physiologic functions including cellular proliferation, acid-base balance, transport of ammonia between tissues, and antioxidant synthesis [1-3]. Glutamine supplementation stimulates an increase in protein synthesis in the muscle, improves glycogen re-synthesis and can lead to an improvement in performance $[4,5]$. Glutamine has been shown to increase fluid and electrolyte absorption in both animal and human models [6]. Recently, consumption of an alanine-glutamine dipeptide was reported to enhance

Corresponding author: Heidar Sajedi, Ph.D. candidate, research field: sport nutrition. fluid uptake and reduce the magnitude of performance decrement during exercise to exhaustion under hypohydrated conditions [5]. Furthermore, the alanine-glutamine dipeptide was shown to be significantly more effective than water alone. This has important implications during athletic performance, where dehydration can play an important role in the outcome of a contest. For instance, a significant performance decrement has been shown with hypohydration levels of only $2 \%$ in basketball players $[7,8]$. Nearly half of professional basketball players evaluated pervious to competitive games were found to be dehydrated prior to the onset of a basketball game, and that fluid intake during the games was not able to compensate for the pregame hypohydration [9]. If the body is lacking sufficient levels of amino acids, both pre- and post-exercise, the result may be negative protein balance, leading to detrimental side-effects such as muscle wasting and delayed exercise recovery [10]. It is essential that athletes consume sufficient amounts of supplementation while appropriately timing their supplementation consumption in order to 
experience a positive nitrogen balance and eventual muscle hypertrophy $[11,12]$. A lot of athletes and exercisers have turned to protein supplements to meet these excess demands on the body. Many studies have been performed proving the positive impact of protein consumption pre- and post-exercise [13-17]. The ISSN (International Society of Sports Nutrition) [11] position stand on protein and exercise further documents the benefit of protein consumption pre- and post-exercise. In addition to timing, type of supplementation consumed has been shown to affect the overall benefits experienced by athletes and measured by researchers $[11,18]$. Basketball has been described as an intermittent sport, being physically very demanding, requiring players to frequently repeat bouts of intense actions (sprinting, shuffling, jumping) with jogging, walking or short periods of recovery [19]. In order to play successfully, basketball players must be physically well prepared by having optimally developed levels of explosive power, agility, anaerobic power and anaerobic capacities [20-22]. In basketball, there are a lot of factors that influence the chance to reach an optimal performance [23]. Until now, by describing different physical, physiological and functional characteristics in the basketball players, it has been afforded importance to the energetic demands that are going to increase performance [24]. To determine if any one supplementation type is more beneficial than another or how many doses of them has the best effect on the athletics body and performance, more studies should be performed. So the purpose of this study was to investigate the efficacy of two different doses $(1 \mathrm{~g}$ per $500 \mathrm{ml}$ and $2 \mathrm{~g}$ per $500 \mathrm{ml})$ of glutamine on basketball performance, including jump power, reaction time and shooting ability during a basketball game.

\section{Materials and Methods}

\subsection{Participants}

Forty men volunteered for this study $(20.4 \pm 1.6$ years old; height: $188.6 \pm 8.7 \mathrm{~cm}$; body mass: $76.5 \pm$
$7.9 \mathrm{~kg}$; Body fat: $12.21 \pm 1.2 \%$ ). All players had played at national level and they had to play at least 16 games and at least 10 minutes per game in order to be included in the research. All of them were healthy without any history of neuromuscular diseases or reported injury in the previous six months. The subjects were allowed to consume a light meal, vegetables such as tomato and cucumber and chicken at least three hours prior the beginning of the testing sessions and it was the same for all testing sessions. Following an explanation of all procedures, risks, and benefits, each subject gave his informed consent to participate in this study. Subjects were not permitted to use any additional nutritional supplementation during the course of the study. All subjects were selected athletes playing for the University's men's basketball team.

\subsection{Research Design}

The 40 players were randomly assigned to FS (During the first session) $(n=10), \mathrm{W}$ (Only water consumption) $(n=10), \mathrm{G} 1 \quad(1 \mathrm{gr} / 500 \mathrm{ml}$ water concentration of glutamine/daily) $(n=10)$ and $\mathrm{G} 2$ ( $2 \mathrm{gr} / 500 \mathrm{ml}$ water concentration of Glutamine/daily) ( $n$ $=10$ ). The groups were exposed to a pre-test and six weeks later to a post-test testing session. All players in the same group were tested on the same day. All subjects were asked to follow their normal diet for the duration of the study.

\subsection{Experimental Procedures}

Subjects were divided into two equally talented teams as determined by the team's player captains. The team members remained the same for each game. Prior to each testing session, all subjects performed a 10-min dynamic warm-up. This warm-up was the same warm-up these athletes performed prior to every game during the competitive season. Following the warm-up, subjects performed power, reaction and basketball shooting assessments. All testing sessions were supervised by certified strength and conditioning specialists. At the conclusion of the basketball game 
and final hydration intake, subjects performed all performance measures. Order of performance testing was performed in a randomized fashion for both pre-game and postgame assessments. Test-retest reliabilities for all assessments were $\mathrm{R}>0.90$. To quantify vertical jump power, subjects performed five consecutive countermovement jumps. During each jump, subjects stood with their hands on their waist at all times. The subjects were instructed to maximize the height of each jump while minimizing the contact time with the ground between jumps. During each jump, the subject wore a belt connected to a Tendo ${ }^{\mathrm{TM}}$ Power Output Unit (Tendo Sports Machines, Trencin, Slovak Republic). The Tendo ${ }^{\mathrm{TM}}$ unit consists of a transducer attached to the end of the belt which measured linear displacement and time. Subsequently, the velocity of each jump was calculated and power determined. The average peak and mean power outputs for all five jumps were recorded. Lower body reaction time was measured with a 20-s reaction test on the Quick Board $^{\text {TM }}$ (The Quick Board, LLC, Memphis, TN) reaction timer. Prior to, and following each game, a pre-determined basketball shooting circuit was performed. The circuit required all subjects to shoot 5 balls from 6 different locations on the court. The total number of successful shots was recorded. The difference between the pregame and post-game shooting performance was calculated and analyzed. Body mass was determined $10 \mathrm{~min}$ prior to the warm-up and immediately following post-game data collection.

\subsection{Statistical Analyses}

Statistical software SPSS (version 17 for windows, Inc., Chicago, IL) was used for data analysis. Mean and standard deviation values were calculated for each variable. All performance data were analyzed using a one-way repeated measures analysis of variance. In the event of a significant F-ratio, post hoc comparisons using the Fisher's least square difference method was applied to determine pairwise differences. A criterion alpha level of $P \leq 0.05$ was used to determine statistical significance.

\section{Results}

No significant difference $(P=0.396)$ in urine specific gravity was showed between trials. During the FS (first session), subjects lost $1.86 \pm 0.42 \mathrm{~kg}$, this was equivalent to a $2.7 \%$ loss of their body mass. This was significantly greater than that seen during any other experimental trial (Fig. 1). Fluid intake was not significantly different between only water consumption, the first concentration of glutamine and the second concentration of glutamine $(1.62 \pm 0.37 \mathrm{~L})$. FS (During the first session), W (Only water consumption), G1 (The first concentration of glutamine) and G2 (The second concentration of Glutamine) amounts are showed as mean. According to Fig. 1, by increasing the glutamine doses, body mass increased too. The shooting percentage for the subjects that were under the first concentration of glutamine treatment was $14.6 \%$ and $12.6 \%$ more than the shooting percentage for the subjects that were under the first session treatment and water consumption treatment, respectively. There was significant difference between the treatments for the peak and mean vertical jump power at $P<0.01$ (Fig. 2). The results indicated that basketball players lose nearly $2.7 \%$ of their body mass during a game in which they do not rehydrate. According to the results, there were significant differences between the treatments and the second concentration of glutamine treatment had the most effect on the reaction time improvement at $P<$ 0.01 in compare to the other treatments. Glutamine treatment both in the first and second doses had the significant and positive effect on the reaction time in compare to the two others treatments, so there was significant difference between treatments for the reaction time at $P<0.01$ (Fig. 3). The results showed positive and significant effect of glutamine treatment on the shooting ability percent, especially the second doses of glutamine had the most effect on the shooting 


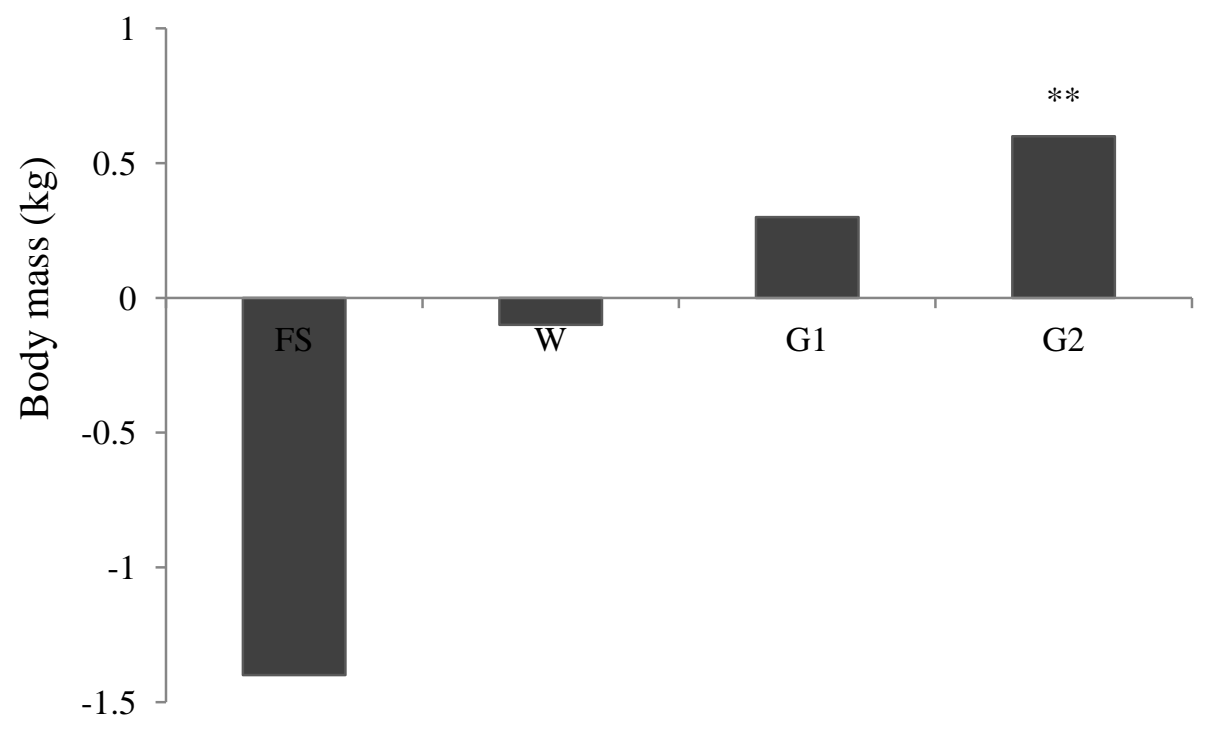

Fig. 1 Change in Body Mass.

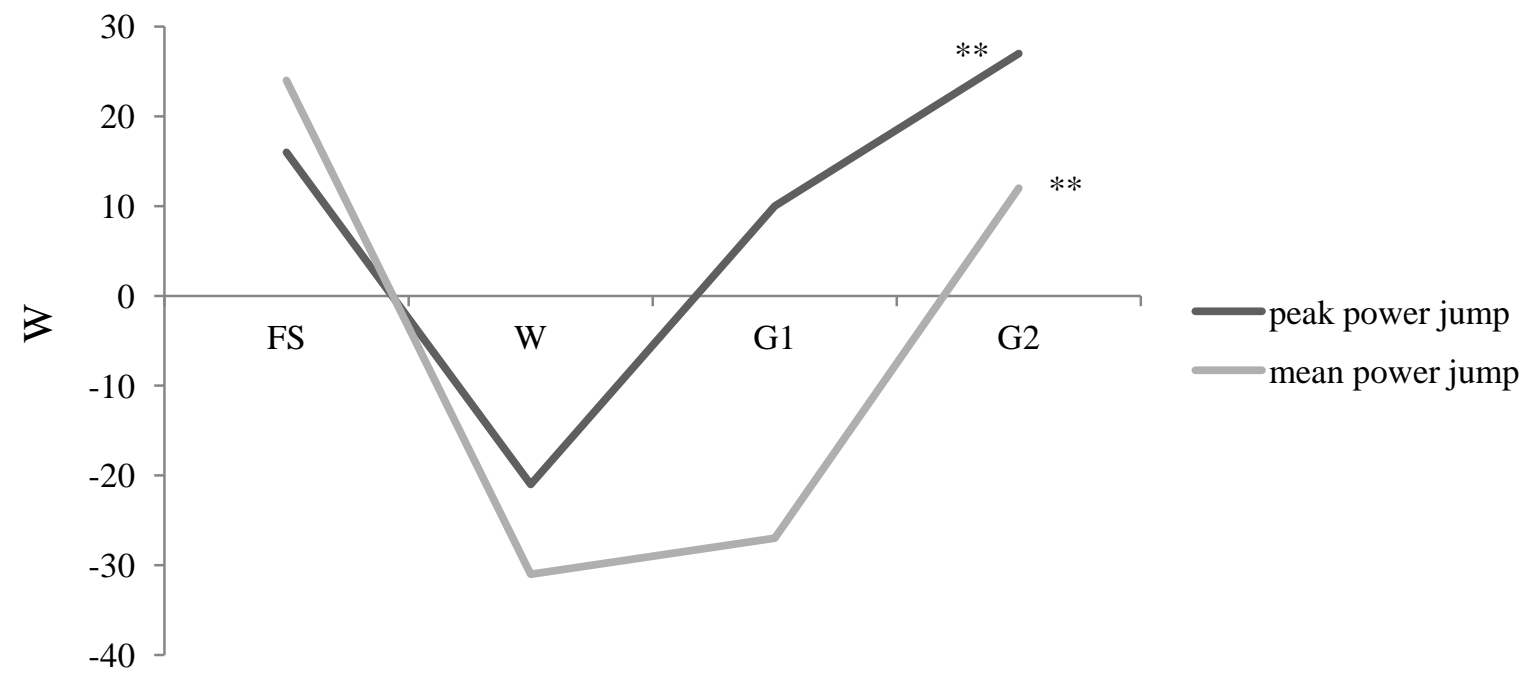

Fig. 2 Peak Vertical Jump Power and Mean Vertical Jump Power.

ability percent in compare to the first doses of glutamine at $P<0.01$. Also, the results showed water consumption treatment can increase shooting ability percent in compare to the normal condition (Fig. 4).

\section{Discussion}

According to the Bassini-Cameron et al. [25], consumption of glutamine prevents ammonium accumulation and glutamine can increase exercise tolerance and power. Researchers have shown that acute supplementation of a glutamine and maltodextrin combination two hours before exercise is more efficient in preventing anaerobic power decrease than the consumption of a pure carbohydrate or glutamine in repeated bouts of the RAST (Running Based Anaerobic Sprint Test) protocol. RAST was devised at the University of Wolverhampton in the UK, and involves six sprints over 35 meters with a 10 second recovery between each sprint, and provides measurements of peak power, average power and minimum power along with a fatigue index. Supplementation with both carbohydrate and peptide 


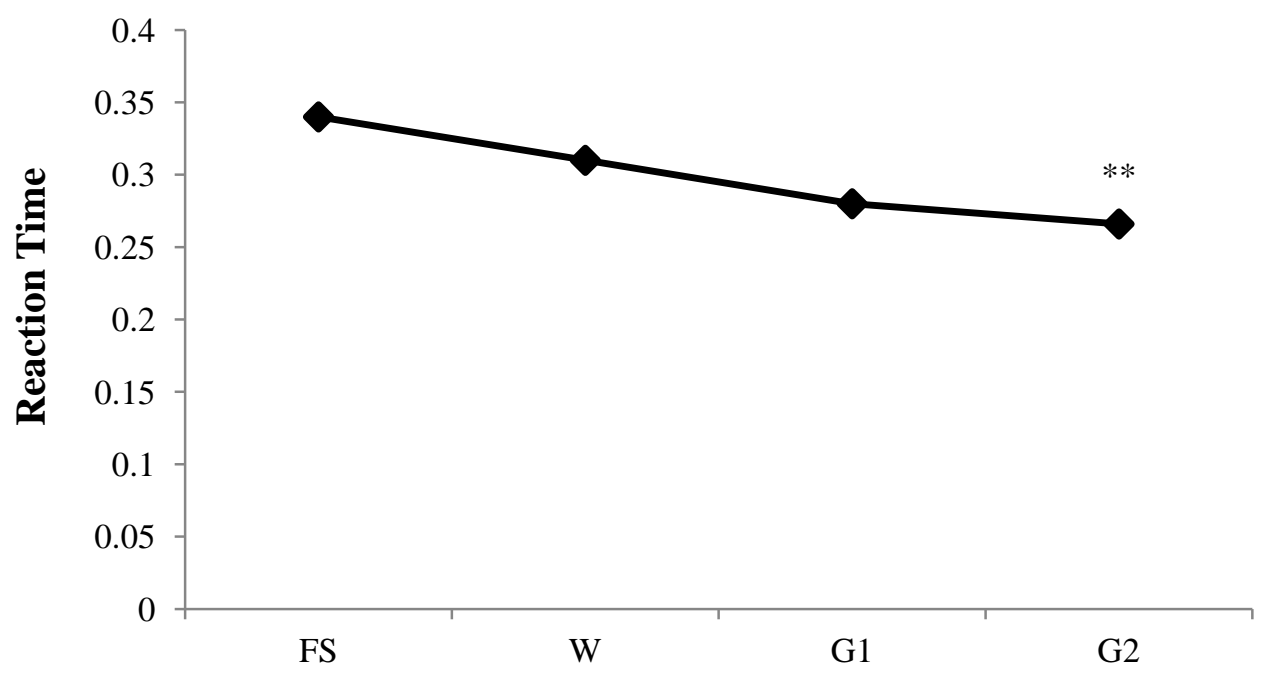

Fig. 3 Reaction time amounts under different treatments.

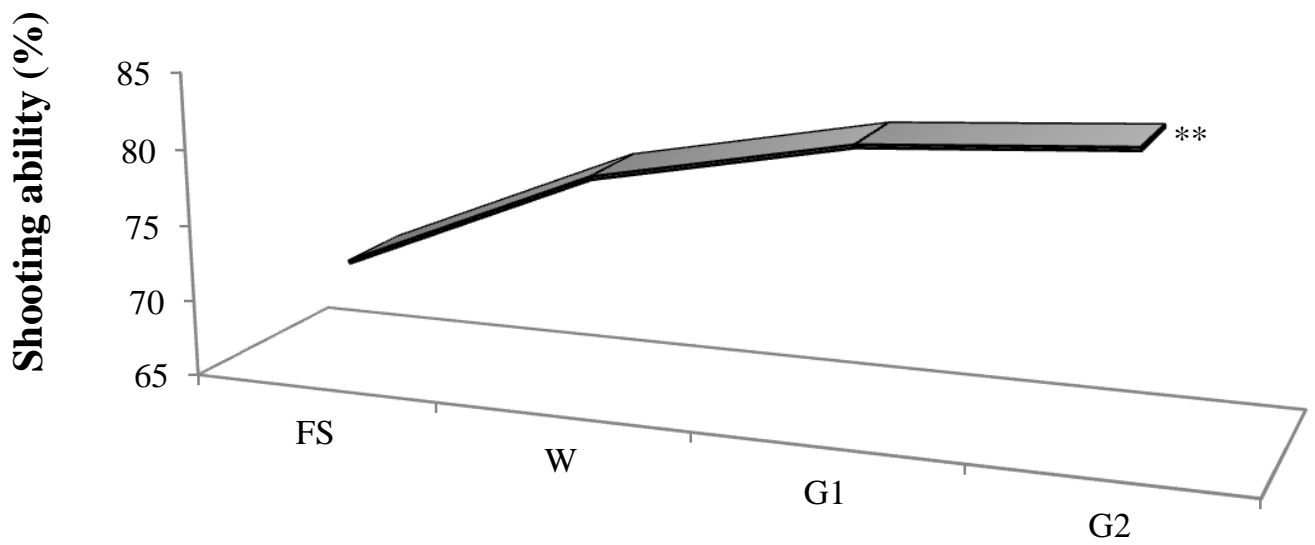

Fig. 4 Shooting ability percent under different treatments.

glutamine improved the physical performance of athletes during repeated handball competitions [26]. Although the decreases in anaerobic power and field goal percentage had no significant difference, the results suggest that the combination of high intensity, moderate duration exercise, and fluid restriction might be detrimental to performance [27]. Glutamine supplementation managed to prevent a decrease of maximum and minimum power. It has been shown that ingestion of pure glutamine promoted muscle glycogen re-synthesis during recovery from exhaustive exercise [28]. Glutamine supplementation had significant and positive effects on the aerobic, anaerobic energy system and power performance of the handball players and also, caused to decrease the blood lactate under post-exercise condition [29]. Despite a significant loss of body fluid during FS, subjects were able to maintain jump power during the game, but basketball shooting performance was significantly impaired. The results showed that jump power is maintained following 
dehydration protocols that elicited a $2.5 \%$ and a $5.0 \%$ loss of body mass. Dehydration has been shown to impair basketball shooting performance in several studies [30]. The mechanism that may have contributed to a decrease in shooting percentage may be fatigue relating to the hydration stress. A recent investigation has indicated that moderate levels of dehydration ( $4 \%$ body mass loss) can result in significant alterations in afferent neural processing [31].

\section{Conclusion}

The results indicated that the second concentration of glutamine treatment had the most effects on the studied trails and changed the trails amount significantly. The glutamine treatments had the more effects on the studied trails in compare to the other treatments. Increasing glutamine doses can also cause the significant effects on the trails. Although the finding from the current study were statistically significant and improved the overall knowledge of glutamine supplementation and basketball players, more studies comparing the consumption of different doses of glutamine under pre- and post-exercise are needed to determine the glutamine effects on the energy systems and improving power performance. Although the results were indicated the significant effects of glutamine on the studied parameters, this study should be performed on the different men and women sport groups and the results may vary depending on the sport type, doses of supplementation and other conditions that will be studied.

\section{Practical Applications}

The combination of a controlled undulating resistance training program with pre- and post-exercise glutamine supplementation had a significant impact on performance and body composition factors. The increasing of glutamine doses can be have more effect on the power improving but should be found the limit of the glutamine to prevent the negative effects.

\section{Acknowledgements}

The authors wish to thank all the athletes who participated in this study.

\section{References}

[1] Curi, R., Lagranha, C. J., Doi, S. Q., Sellitti, D. F., Procopio, J., Pithon-Curi, T. C., and Newsholme, P. 2005. "Molecular Mechanisms of Glutamine Action." Journal of Cellular Physiology 204 (2): 392-401.

[2] Newsholme, P., Procopio, J., Lima, M. M. R., Pithon-Curi, T. C., and Curi, R. 2003b. "Glutamine and Glutamate: Their Central Role in Cell Metabolism and Function." Cell Biochemistry and Function 21 (1): 1-9.

[3] Rutten, E. P., Engelen, M. P., Schols, A. M., and Deutz, N. E. 2005. "Skeletal Muscle Glutamate Metabolism in Health and Disease: State of the Art." Current Opinion in Clinical Nutrition and Metabolic Care 8 (1): 41-51.

[4] Favano, A., Santos-Silva, P. R., Nakano, E. Y., Pedrinelli, A., Hernandez, A. J., and Greve, J. M. D. 2008. "Peptide Glutamine Supplementation for Tolerance of Intermittent Exercise in Soccer Players." Clinics 63 (1): 27-32.

[5] Hoffman, J. R., Ratamess, N. A., Kang, J., Rashti, S. L., Kelly, N., Gonzalez, A. M., Stec, M., Andersen, S., Bailey, B. L., Yamamoto, L. M., Hom, L. L., Kupchak, B. R., Faigenbaum, A. D., and Maresh, C. M. 2010. "Examination of the Efficacy of Acute LAlanyl-L-Glutamine during Hydration Stress in Endurance Exercise." Journal of International Society and Sports Nutrition 7 (8): 7-8.

[6] Lima, A. A., Carvalho, G., Figueiredo, A. A., Gifoni, A. R., Soares, A. M., Silva, E. A., and Guerrant, R. L. 2002. "Effects of an Alanyl-glutamine-based Oral Rehydration and Nutrition Therapy Solution on Electrolyte and Water Absorption in a Rat Model of Secretory Diarrhea Induced by Cholera Toxin." Nutrition 18 (6): 458-62.

[7] Dougherty, K. A., Baker, L. B., Chow, M., and Kenney, W. L. 2006. "Two Percent Dehydration Impairs and Six Percent Carbohydrate Drink Improves Boys Basketball Skills." Medicine Science and Sports Exercise 38 (9): 1650-8.

[8] Hoffman, J. R., Stavsky, H., and Falk, B. 1995. "The Effect of Water Restriction on Anaerobic Power and Vertical Jumping Height in Basketball Players." International Journal of Sports Medicine 16 (4): 214-8.

[9] Osterberg, K. L., Horswil, C. A., and Baker, L. B. 2009. "Pregame Urine Specific Gravity and Fluid Intake by National Basketball Association Players during Competition." Journal of Athletic Training 44 (1): 53-7.

[10] Phillips, S. M., Parise, G., Roy, B. D., Tipton K. D., Wolfe, R. R., and Tamopolsky, M. A. 2002. 
"Resistance-Training-Induced Adaptations in Skeletal Muscle Protein Turnover in the Fed State." Canadian Journal of Physiology and Pharmacology 80 (11): 1045-53.

[11] Campbell, B., Kreider, R., Ziegenfuss, T., La Bounty, P., Roberts, M., Burke, D., Landis, J., Lopez H. and Antonio, J. 2007. "International Society of Sports Nutrition Position Stand: Protein and Exercise." Journal of the International Society of Sports Nutrition 4 (1): 8.

[12] Kerksick, C. and Leutholtz, B. 2005. "Nutrient Administration and Resistance Training." Journal of the International Society of Sports Nutrition 2 (1): 50-67.

[13] Andersen, L. L., Tufekovic, G. and Zebis, M. K. 2005. "The Effect of Resistance Training and Combined with Timed Ingestion of Protein Muscle Fiber Size and Muscle Strength.” Metabolism 54 (2): 151-6.

[14] Cribb, P., Williams, A. D., Carey, M. F. and Hayes, A. 2006. "The Effect of Whey Isolate and Resistance Training on Strength, Body Composition, and Plasma Glutamine." International Journal of Sport Nutrition and Exercise Metabolism 16 (5): 494-509.

[15] Flakoll, P. J., Judy, T., Flinn, K., Carr, C. and Flinn, S. 2004. "Postexercise Protein Supplementation Improves Health and Muscle Soreness during Basic Military Training in Marine Recruits." Journal of Applied Physiology 96 (3): 951-6.

[16] Hulmi, J. J., Volek, J. S., Selanne, H. and Mero, A. A. 2005. "Protein Ingestion prior to Strength Exercise Affects Blood Hormones and Metabolism." Medicine and Science in Sports and Exercise 37: 1990-7.

[17] Willoughby, D. S., Stout, J. R. and Wilborn, C. D. 2007. "Effects of Resistance Training and Protein plus Amino Acid Supplementation on Muscle Anabolism, Mass, and Strength.” Amino Acids 32 (4): 467-77.

[18] Wilson, J. and Wilson, G. 2006. "Contemporary Issues in Protein Requirements and Consumption for Resistance Trained Athletes." Journal of the International Society of Sports Nutrition 3 (1): 7-27.

[19] Ben Abdelkrim, N., El Fazaa, S., and El Ati, J. 2006. "Time-motion Analysis and Physiological Data of Elite Under-19-year-old Basketball Players during Competition.” British Journal of Sports Medicine 41 (2): 69-75.

[20] Apostolidis, N., Nassis, G. P., Bolatoglou, T., and Geladas, N. D. 2004. "Physiological and Technical Characteristics of Elite Young Basketball Players." Journal of Sports Medicine and Physical Fitness 44 (2): 157-63.

[21] Ben Abdelkrim, N., Chaouachi, A., Chamari, K., Chtara,
M., and Castagna, C. 2010. "Positional Role and Competitive-Level Differences in Elite-Level Men's Basketball Players." Journal of Strength and Conditioning Research 24 (5): 1346-55.

[22] Delextrat, A., and Cohen, D. 2008. "Physiological Testing of Basketball Players: Toward a Standard Evaluation of Anaerobic Fitness." Journal of Strength and Conditioning Research 22 (4): 1066-72.

[23] Sanchez, M. 2007. "Fitness in Basketball." Apunts 42 (154): 99-107. (in Spain)

[24] Vaquera, A., Rodriguez, J. A., Villa, J. G., Garcia, J., and Avila, C. 2002. "Physiological Biomechanical Qualities of the Young Player of League EBA." Motor: Science Journal of Physical Activity and Sport 9: 43-63. (in Spain)

[25] Bassini-Cameron. A., Monteiro, A., Gomes, A., Wemeck-De-Castro, J. P., and Cameron, L. 2008. "Glutamine Protects against Increases in Blood Ammonia in Football Players in an Exercise Intensity Dependent Way." Journal of Sport Medicine 42 (4): 6-26.

[26] Khorshidi-Hosseini, M., and Nakhostin-Roohi, B. 2013. "Effect of Glutamine and Maltodextrin Acute Supplementation on Anaerobic Power." Asian Journal of Sport Medicine 4 (2): 131-6.

[27] Hoffman, J. R., Stavsky, H., and Folk, B. 2007. "The Effect of Water Restriction on Anaerobic Power and Vertical Jumping Height in Basketball Players." Physiology and Biochemistry 16 (4): 214-8.

[28] Bowtell, J. L., Gelly, K., Jackman, M. L., Patel, A., Simeoni, M., and Renie, M. J. 1999. "Effect of Oral Glutamine on Whole Body Carbohydrate Storage during Recovery from Exhaustive Exercise." Journal of Applied Physiology 86 (6): 1770-7.

[29] Sajedi, H., Kaldirimci, M., Tugrulhan Sam, C., Mizrak, O., and Sivrikaya, M. H. 2015. "Glutamine Supplementation and Anaerobic Power Outputs of Handball Players." Italian Journal Archive of Medical Science In Press. (in Italian)

[30] Baker, L. B., Kougherty, K. A., Chow, M., and Kenney, W. L. 2007. "Progressive Dehydration Causes a Progressive Decline in Basketball Skill Performance." Medicine Science and Sports Exercise 39 (7): 1114-23.

[31] Judelson, D. A., Maresh, C. M., Farrell, M. J., Yamamoto, L. M., Armstrong, L. A., Kraemer, W. J., Volek, J. S., Speiring, B. A., Casa, D. J., and Anderson, J. M. 2007. "Effect of Hydration State on Strength, Power, and Resistance Exercise Performance." Medicine Science and Sports Exercise 39 (10): 1817-24. 